\title{
ANALYZING THE IMPACT OF REINFORCEMENT ADDITION ON THE MECHANICAL PROPERTIES OF ALUMINUM A356 ALLOY
}

\section{ADEFEMI O. OWOPUTI*, FREDDIE L. INAMBAO \& WILLIAM S. EBHOTA}

Department of Mechanical Engineering University of KwaZulu-Natal, Durban, South Africa

\begin{abstract}
The need to have materials which can respond satisfactorily to dynamic changes encountered in service conditions have driven engineering and scientific researchers into fabrication of a unique class of engineering materials known as functionally graded materials (FGM). Consisting of a combination of metal and ceramic reinforcement, FGM exhibit properties which are not achievable with monolithic materials. In this study, the author studied the impact of the variation in size and weight-percent of silicon carbide (SiC) reinforcement particles on the properties of fabricated Al-SiC FGM composites. Two sets containing three FGM samples were fabricated. The SiC configuration by weight-percent and size

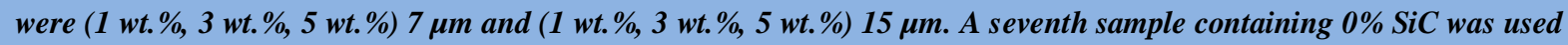
as a control. The experimental results indicate that the introduction of $\mathrm{SiC}$ reinforcement into the matrix impacts on the compressive and shear behavior of aluminum A356 alloy. The sample with the combination of the finest granularity (7 $\mu \mathrm{m})$ and highest percentage-weight (5 wt.\%) displayed the highest compressive strength and Young's modulus values of 3.11 GPa and 6.39 GPa respectively, with a shear strength and shear modulus of 14.4 GPa and 9.29 GPa respectively.
\end{abstract}

KEYWORDS: Metal Matrix Composites, Compressive Strength, Young's Modulus, Silicon Carbide \& Aluminum A356 Alloy

Received: Apr 06, 2021; Accepted: Apr 26, 2021; Published: Jun 14, 2021; Paper Id.: IJMPERDAUG20214

\section{INTRODUCTION}

Metal matrix composites (MMCs) are materials with wide range of engineering applications and potentials [1]. During service, MMCs are subjected to varied load capacities, which oftentimes are at elevated temperatures. In automobile manufacture, parts such as the pistons and the shock absorbers are required to retain their structural integrity under compressive forces, hence, the compressive properties of the engineering material adopted for the production of these parts are of great importance. Properties such as yield strength and modulus are also critical engineering properties in relation to automobile applications.

Modern engineering applications have highlighted the need for materials with dynamic property combinations such as, strength, toughness, thermal and wear resistivity, among others. Achieving these property combinations was a huge challenge in times past, more so with monolithic materials. Traditionally, the choice of monolithic material in an engineering application aims to tackle a specific engineering challenge [2]. Herein lies the limitation of these type of materials. This limitation has driven research into the development of advanced engineering materials capable of exhibiting contradictory properties in extreme service conditions without compromise to their structural integrity.

In a bid to manufacture tailor-made materials for specific engineering applications, the concepts of materials alloying and composites manufacture has come to the fore. The applications of alloys and composites date 
as far back as $2000 \mathrm{BC}$ in the making of various tools and weapons. Alloys are a combination of two or more different materials, usually in liquid phase, to obtain a unique material with properties different from the parent materials after solidification. Composite materials are special engineering materials developed from the combination of two or more materials, usually in different phases. The individual materials that make up an alloy are indistinguishable from each other after solidification, but the material constituents of composites can be distinguished under microscopic examination. Furthermore, regarding composite formation, the position of reinforcing materials within the base matrix of the composite material can be influenced so as to obtain or improve on the desired property(ies) required of the material. As technology advances, the importance of alloys and composite materials for various automobile, spacecraft, military, electronic and medical applications cannot be overemphasized. Research into various types of composite materials such as polymer matrix $[3,4]$, carbon matrix, ceramics matrix [5] and metal matrix composites [6,7] have been on the increase in recent years as researchers are constantly seeking ingenious ways to develop materials to meet the ever-dynamic engineering demands of modern times.

Metal matrix composites are engineering materials made up of two or more materials with one of the materials (the matrix) being metal and the other material(s) (the reinforcement) being a ceramic or organic material [8]. The reinforcement materials, introduced to the matrix material to improve on their properties, can be in the form of particulates or a continuous or discontinuous fiber. Particulate reinforcement has often been favored over fiber reinforcement due to the ability to control the resulting composites' properties by varying the granularity and volume ratio of the reinforcement $[9,10]$. Aluminum has found use in various engineering applications owing to its properties of formability, good ductility, lightweight as well as its abundance in nature [11]. When reinforced with particles of ceramics such as $\mathrm{SiC}$ in adequate proportion and particle size, the mechanical properties of aluminum alloy can be improved upon. Numerous research studies on the effects of reinforcements on the behavior of aluminum metal during service have been conducted.

In a study conducted by Xiaoyu, et al. [12], the effect of melting temperature, mold temperature and rotating speed on the microstructure and the mechanical behavior of fabricated $\mathrm{Al}-\mathrm{SiC}$ piston was investigated. The gradient distribution of the reinforcing particles was attributed to the centrifugal force which acted on the particles in the aluminum matrix during the casting process, thereby forcing a larger concentration of the particles towards the head of the piston. The good wear and hardness properties subsequently observed at the piston head was attributed to the presence of the $\mathrm{SiC}$ reinforcement. In a similar research conducted by Pawar and Utpat [13], a composite material using $\mathrm{SiC}$ reinforcement in aluminum matrix was fabricated through centrifugal casting technique. The authors sought to determine the suitability of this type of material composite in the production of power transmission elements such as gears. The hardness and the toughness of the fabricated composite was reported to have increased with an increase in the $\mathrm{SiC}$ content of the material. Using modelling and finite element analysis, the suitability of the material as a power transmission material was further established by the authors. The suitability of aluminum composites in the production of electrical and electronic parts due to good coefficient of thermal expansion have been established in literature $[8,14,15]$.

Radhika and Raghu [16] conducted a study on the effect of different types of reinforcing particles, $\mathrm{B}_{4} \mathrm{C}, \mathrm{SiC}, \mathrm{Al}_{2} \mathrm{O}_{3}$ and $\mathrm{TiB}_{2}$, on the mechanical behavior of $\mathrm{Al}-12 \mathrm{Si}$-Cu-based composite fabricated through a centrifugal technique. It was reported that the outer zone of the fabricated hollow cylindrical composite exhibited a higher hardness value when compared to the middle and the inner zone of the composite. This was attributed to the presence of a concentrated amount of the reinforcement particles observed at the outer zone and none at the core where the effect of centrifugal force is least. From 
the four composites fabricated, $\mathrm{Al} / \mathrm{TiB}_{2}$ composite was found to exhibit the lowest wear rate due to the high density of the $\mathrm{TiB}_{2}$ reinforcement [16]. Furthermore, a change in the concentration of reinforcement in the matrix of fabricated FGM composites have been reported in literature [17, 18].

Functionally graded materials (FGM) are a unique type of engineering materials with compositional and property variances along the material's geometry. The concept of FGM arose from the need to manufacture an engineering material whose behavior can be influenced in a gradient pattern across its length or cross-section in a controlled process, to suit a predetermined application. In other words, the properties of the FGM such as mechanical, thermal, tribological, and electrical are influenced across the material bulk by closely varying the concentration of the reinforcement material within the matrix. The interest in FGMs and their potential applications in industries such as aviation, medical, automobile, and military have driven engineers into in-depth research on the various fabrication and optimal processing techniques in the manufacture of FGMs. Fabrication techniques such as deposition [19, 20], powder metallurgy [21], and casting techniques [22, 23] have been conducted and well documented in literature.

In this study, the author aimed to fabricate a functionally graded $\mathrm{Al}-\mathrm{SiC}_{\mathrm{p}}$ composites by means of a liquid metallurgy process. The impact of increase in size and weight-percent of SiC particle addition, on the compressive and shear strength behavior of fabricated composite was studied and reported on accordingly. The composite materials were fabricated using centrifugal casting techniques. This technique has been identified in literature as the most suitable casting process due to its cost-effectiveness for mass production, relative ease of operation, and flexibility of process [24, 25].

\section{MATERIALS AND METHODOLOGY}

Commercially pure aluminum ingots and silicon carbide particles were adopted as the base matrix and reinforcement for the cast composites fabricated through centrifugal technique. Varied weight-percent of the SiC particles with average sizes $7 \mu \mathrm{m}$ and $15 \mu \mathrm{m}$ were introduces into the matrix to produce Al-SiC composites.

Each composite material was prepared by determining the weight of the aluminum ingots and then charging it into the furnace with the temperature set to $750{ }^{\circ} \mathrm{C}$. With the aid of a mechanical stirrer, the molten aluminum was stirred to create a vortex into which a measured weight-percent $\left(1,3\right.$, and 5) of the $\mathrm{SiC}$ particle reinforcement, preheated at $300{ }^{\circ} \mathrm{C}$, was introduced. The stirring continued until the reinforcement particles were homogeneously dispersed in the aluminum matrix. The molten composite was poured into the vertical rotating mold cavity of a centrifugal machine. The distance travelled by individual reinforcement particle along the cross-section of cast samples has been found to be influenced by the density differential between the matrix and the reinforcements, the size and shape of the particles and the centrifugal force exerted on the individual particles [26]. The parameters adopted for the casting process are shown in Table 1.

Table 1: Casting Parameters

\begin{tabular}{|l|c|}
\hline Melting temperature & $750^{\circ} \mathrm{C}$ \\
\hline Melting Time & $10 \mathrm{Min}$ \\
\hline Reinforcement preheated temp & $300^{\circ} \mathrm{C}$ \\
\hline Rotating speed of mold & $800 \mathrm{rpm}$ \\
\hline
\end{tabular}

Six composite samples were fabricated from different combinations of the SiC reinforcement weight-percent and sizes. The seventh sample had $0 \%$ reinforcement addition and served as a control sample. The samples were prepared for the compression test in accordance to ASTM E9 standard. The SiC specification contained in the individual cast samples are 
shown in Table 2.

Table 2: Matrix-Reinforcement Specification of Fabricated Composites

\begin{tabular}{|l|c|c|c|c|c|c|c|}
\hline \multicolumn{1}{|c|}{ Sample Label } & A & B & C & D & E & F & G \\
\hline SiC $_{\mathrm{p}}$ wt. $\%$ & 1 & 3 & 5 & - & 1 & 3 & 5 \\
\hline Average $\mathrm{SiC}_{\mathrm{p}} \operatorname{size}(\mu \mathrm{m})$ & 7 & 7 & 7 & - & 15 & 15 & 15 \\
\hline
\end{tabular}

Energy dispersive X-ray analysis (EDX) performed on the cast FGM composites shows the elemental constituents of each sample as illustrated in Table 3. The $\mathrm{SiC}$ reinforcement particle was determined to contain $54.36 \% \mathrm{Si}, 42.63 \% \mathrm{C}$, and $3.01 \% \mathrm{O}$.

Table 3: Elemental Constituent of the Fabricated Al-SiC Composites

\begin{tabular}{|c|c|c|c|c|l|}
\hline Sample & Si (\%) & $\mathbf{C ~ ( \% )}$ & $\mathbf{O}(\boldsymbol{\%})$ & Fe (\%) & Al (\%) \\
\hline A & 0.85 & 5.81 & 1.28 & 0.95 & Remainder \\
\hline B & 0.93 & 7.04 & 1.80 & 0.81 & Remainder \\
\hline C & 1.37 & 16.98 & 3.12 & 0.62 & Remainder \\
\hline D & - & 5.83 & 1.52 & 0.36 & Remainder \\
\hline E & 0.80 & 5.84 & 1.30 & 0.87 & Remainder \\
\hline F & 0.87 & 7.08 & 1.85 & 0.69 & Remainder \\
\hline G & 1.29 & 16.85 & 3.24 & 0.48 & Remainder \\
\hline
\end{tabular}

The SiC particles as observed under SEM imaging in figure 1 showed that the individual particles of the SiC reinforcements were irregularly shaped with jagged edges possibly as a result of crushing of the particles to desired sizes. The spacing between the silicon and carbon particles in a SiC atom is reported in literature to be about $1.46 \AA$.
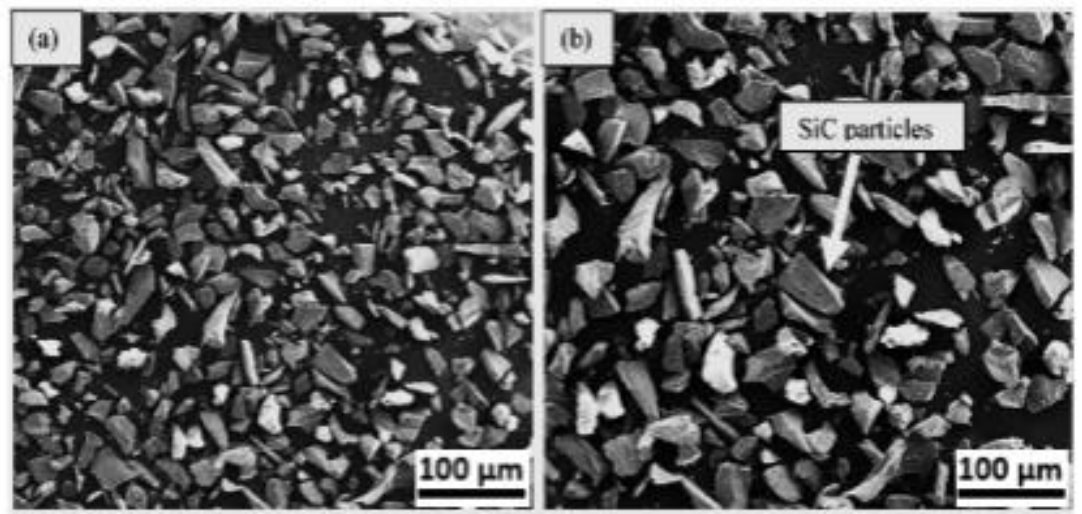

Figure 1: SEM Morphology of (a) $7 \mu \mathrm{m}$ and (b) $15 \mu \mathrm{m} \mathrm{SiC} \mathrm{Reinforcement} \mathrm{Particles.}$

$\mathrm{SiC}$ has been reported to possess properties such as high thermal stability, high wear resistance, hardness, and high melting temperature, and low manufacturing cost [27, 28], making it one of the most suitable reinforcement materials in the fabrication of metal matrix composites. Good wettability and relatively non-chemical reaction with reinforced matrix at elevated temperatures also lends support to the use of $\mathrm{SiC}$ as reinforcement $[29,30]$.

\section{RESULTS AND DISCUSSIONS}

Compression tests were carried out on the fabricated FGM samples to determine the impact of the size variance and weightpercent of the reinforcement particles on the cast samples. Readings obtained from the MTS universal testing machine for 
each sample were documented and compared against each other.

\subsection{Compressive Strength of Fabricated FGM Composites}

A compressive strength test was carried out on the prepared FGM samples at a constant load rate of $0.3 \mathrm{kN} / \mathrm{s}$, using the MTS universal testing machine. The maximum loads at which each sample failed under compressive force were recorded and used in calculating their individual compressive strength values. Figure 2 shows the test samples after the compression test.

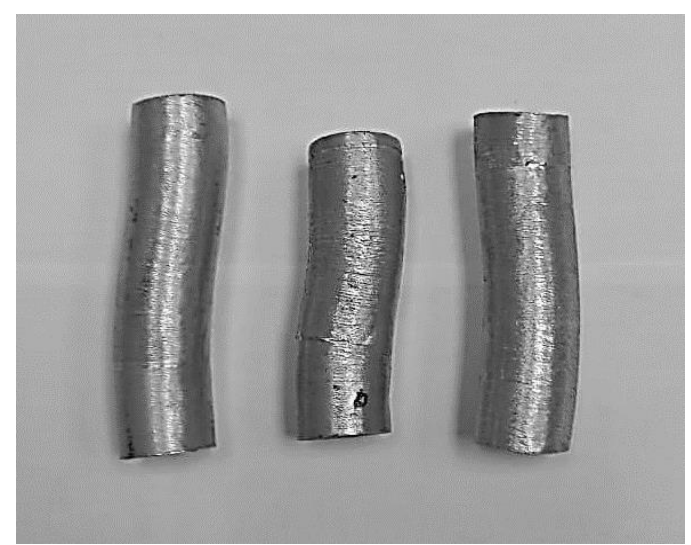

Figure 2: Composite Samples after Compression Test.

It was observed that the inclusion of $\mathrm{SiC}$ particles into the aluminum matrix improved the compressive strength of the composite. When the compressive strengths of samples which containing reinforcements of the same particle sizes were calculated, it was observed that the value of the compressive strength of the material increased as the weight-percent of the particle in the material increased. Samples A, B, and C, which contained 1 wt. $\%, 3$ wt.\%, and 5 wt.\% of $7 \mu \mathrm{m}$ of SiC reinforcement respectively, displayed a compressive strength of $2038 \mathrm{MPa}, 2316 \mathrm{MPa}$, and $3107 \mathrm{MPa}$ respectively. A similar pattern was observed for samples E, F, and G with $1 \mathrm{wt} . \%, 3 \mathrm{wt} . \%$, and $5 \mathrm{wt} . \%$ of $15 \mu \mathrm{m}$ of SiC reinforcement respectively having compressive strength of $1859 \mathrm{MPa}, 2126 \mathrm{MPa}$, and $2271 \mathrm{MPa}$ respectively. The compressive strength value of 1176 MPa was measured for sample D which had no SiC reinforcement. In summary, the results show that the sample with the combination of the smallest size, and the most percentage-weight of $\mathrm{SiC}$ particle reinforcement exhibited the highest compressive strength property as shown in figure 3 . This result agrees with findings in literature $[9,31,32]$ on the effects of particulate reinforcement addition on the compressive strength properties of aluminum matrix. 


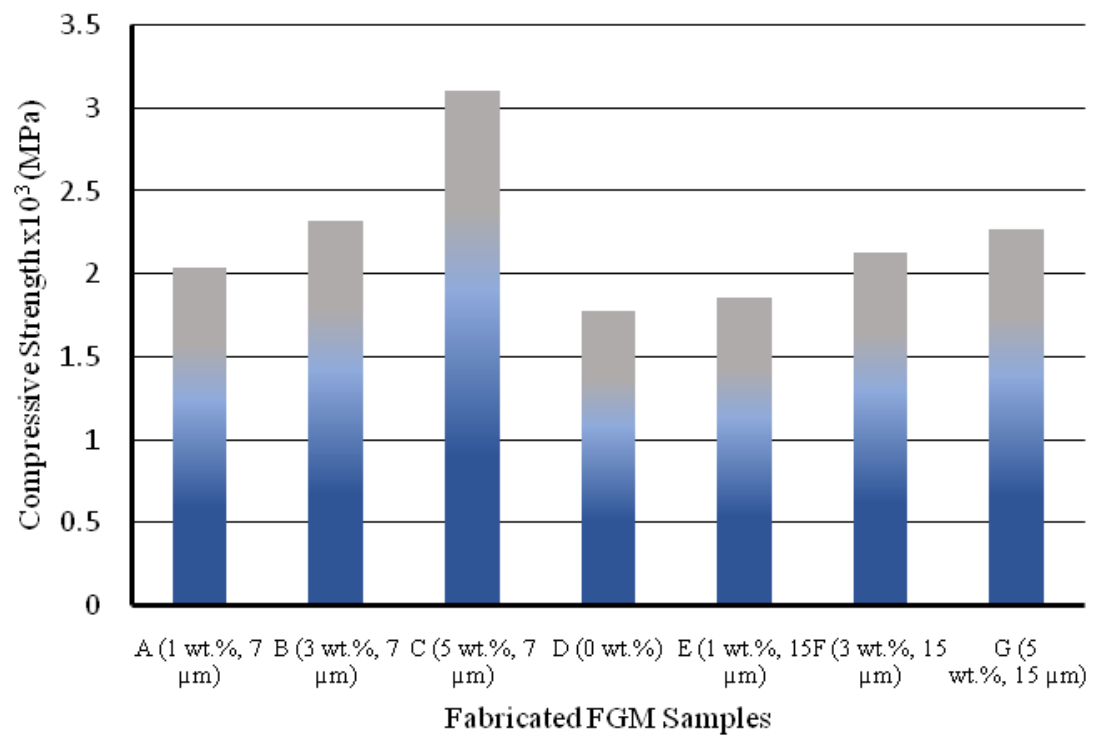

Figure 3: Compressive Strength of Fabricated FGM Samples.

\subsection{Young's Modulus of Fabricated FGM Composites}

The young's modulus of each fabricated composite sample, was calculated from the reading obtained from the UTM.

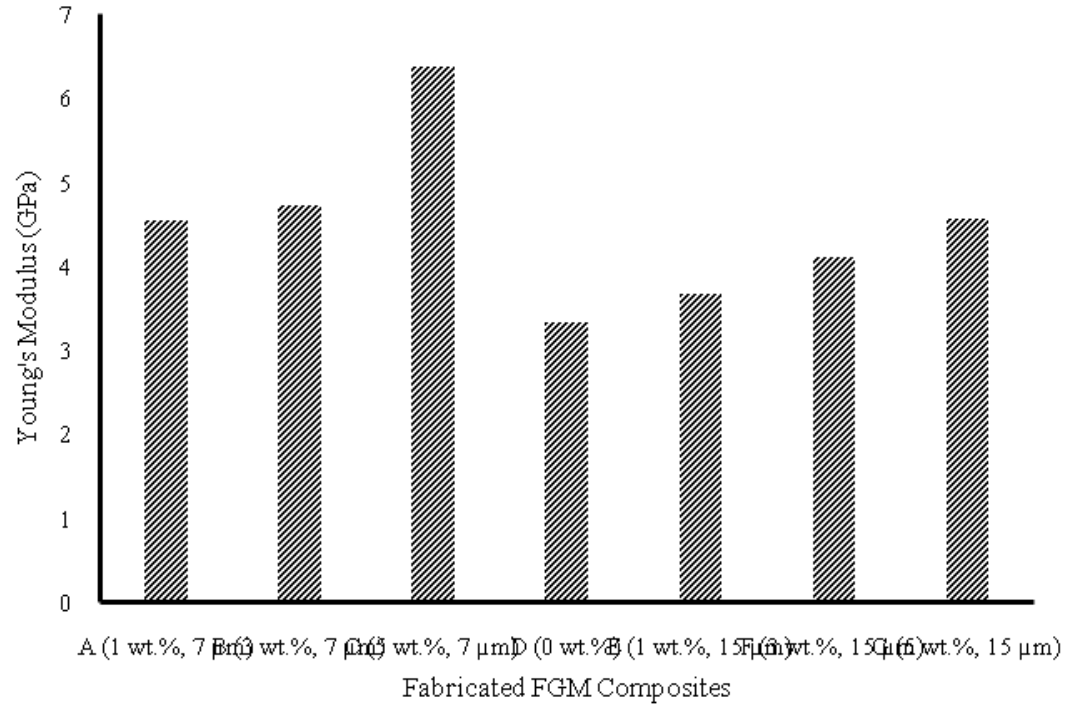

Figure 4: Young's Modulus of Fabricated Composite.

The Young's moduli of the fabricated composites were observed to follow a similar trend regarding the materials' compressive strength with the samples A, B, and C possessing Young's moduli of $4.54 \mathrm{GPa}$, $4.75 \mathrm{GPa}$, and $6.39 \mathrm{GPa}$ respectively, while samples E, F, and G had Young's moduli values of $3.68 \mathrm{GPa}, 4.12 \mathrm{GPa}$, and $4.57 \mathrm{GPa}$ respectively. Sample D with no SiC reinforcement had a modulus value of $3.34 \mathrm{GPa}$. The composite sample which contained the combination of the finest particle size of $7 \mu \mathrm{m}$ and the most weight-percent of 5 wt.\% (sample C) had the highest young's modulus value of $6.39 \mathrm{GPa}$ as shown in Figure 4. 


\subsection{Shear Strength and Modulus of Fabricated FGM Composites}

The shear strength analysis was carried out using the MTS universal testing machine by applying a shear force perpendicular to the surface of the fabricated composites. The maximum force required to cause each composite to fail was recorded and was used to determine their shear strength values. Samples A, B, and C reinforced with SiC particle size of $7 \mu \mathrm{m}$ and $1 \%, 3$ $\%$, and $5 \%$ by weight gave shear strength values of $8.79 \mathrm{GPa}, 10.8 \mathrm{GPa}$, and $14.4 \mathrm{GPa}$ respectively, while samples E, F, and $\mathrm{G}$ reinforced with $\mathrm{SiC}$ particle size of $15 \mu \mathrm{m}$ and $1 \mathrm{wt} . \%, 3 \mathrm{wt} . \%$, and $5 \mathrm{wt} . \%$ by weight displayed shear strength values of 6.97 GPa, 7.18 GPa, and 8.18 GPa respectively. Sample D having no reinforcement addition displayed the least shear strength value of $4.93 \mathrm{GPa}$. Figure 5 shows the composite samples after shearing while Figure 6 is a plot showing the shear strength and shear modulus all the fabricated FGM samples.

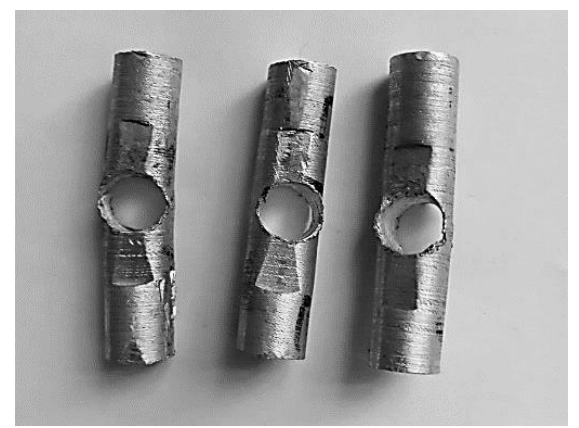

Figure 5: Composite Samples after Shearing.

The cast composites' shear moduli shown as a line graph in figure 5 was obtained from data generated from the MTS universal testing machine during shear test. The shear moduli for samples A, B and C were 7.55 GPa, 8.47 GPa, and 9.29 GPa respectively, while samples E, F, and G had values of 7.15 GPa, 7.17 GPa, and 7.48 GPa respectively. Sample D with no reinforcement addition gave a modulus of $4.22 \mathrm{GPa}$.

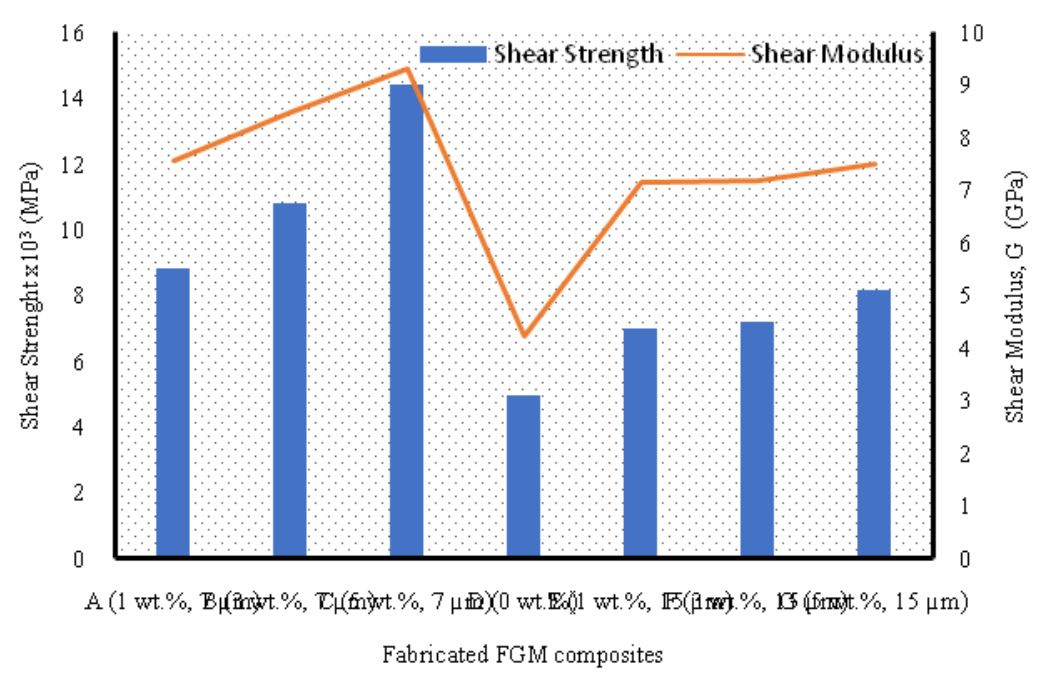

Figure 6: Shear Strength and Shear Modulus all the Fabricated FGM Samples.

The overall mechanical properties of sample $\mathrm{C}$ were observed to be higher than the other cast composites having shear strength and shear modulus values of $14.4 \mathrm{GPa}$ and $9.29 \mathrm{GPa}$. The improved shear values can be attributed to the fine particle size and the high weight-percent of the reinforcement in the sample's matrix. This result agrees with results obtained 
from the work done by Ye, et al. [33] and Rahman and Al Rashed [34].

\section{CONCLUSIONS}

In this paper, functionally graded aluminum metal matrix composites were manufactures through a centrifugal casting technique using predetermined process parameters. The effect of $\mathrm{SiC}$ (particle size and weight percent) addition on the compressive and shear properties of the resulting $\mathrm{Al}-\mathrm{SiC}$ composites were studied and the following conclusions were reached:

- Gradient distribution of $\mathrm{SiC}$ particles was achieved through the centrifugal force acting on the reinforcement particles during centrifugal casting process.

- The addition of $\mathrm{SiC}$ particle reinforcement to the matrix of aluminum alloy significantly improved the compressive and shear strength of the resulting FGM composites.

- Increasing the reinforcement particle ratio in the cast matrix produced a corresponding improvement in the strength of the cast FGM composites.

- The size of particle reinforcement influenced the properties of the cast composites. The composite samples reinforced with particle size of $7 \mu \mathrm{m}$ of $\mathrm{SiC}$ displayed higher compressive and shear strength values when compared to corresponding composite samples reinforced with particle size of $15 \mu \mathrm{m}$ of $\mathrm{SiC}$.

\section{CONFLICT OF INTEREST}

The authors have no conflict of interest to declare.

\section{ACKNOWLEDGEMENT}

The authors acknowledge the Department of Mechanical Engineering of the University of KwaZulu-Natal for their contribution to the success of this study.

\section{REFERENCES}

1. S. O. Akinwamide, M. Lesufi, O. J. Akinribide, P. Mpolo, and P. A. Olubambi, "Evaluation of microstructural and nanomechanical performance of spark plasma sintered TiFe-SiC reinforced aluminium matrix composites, "Journal of Materials Research and Technology, vol. 9, pp. 12137-12148, 2020.

2. Deepinder Singh Aulakh, Sarvesh Kumar \& Ramandeep Singh Cheema, "Unconfined Compressive Strength of Cement Stabilized Pond Ash ",International Journal of Civil, Structural, Environmental and Infrastructure Engineering Research and Development (IJCSEIERD), Vol. 8, Issue 3,pp, 7-14

3. S. O. Akinwamide, O. J. Akinribide, M. Phumlani, O. O. Ayodele, K. L. Mophoso, B. T. Abe, et al., "Influence of heat treatment on microstructural and mechanical behavior of stir cast Al-(TiFe-SiC) composites, "Materials Today: Proceedings, vol. 28, pp. 725-729, 2020.

4. G. Musalaiah, Y Shireesha, P. Kamal Kumar \& P Satyanarayana Raju, "Compressive and Flexural Strength Improvement of Jute Fibre Reinforced Polymer Composite ",International Journal of Mechanical and Production Engineering Research and Development (IJMPERD), Vol. 7, Issue 4, pp, 235-240

5. J.J. Luo and I. M. Daniel, "Characterization and modeling of mechanical behavior of polymer/clay nanocomposites, "Composites science and technology, vol. 63, pp. 1607-1616, 2003. 
6. R. E. Gorga and R. E. Cohen, "Toughness enhancements in poly (methyl methacrylate) by addition of oriented multiwall carbon nanotubes, "Journal of Polymer Science Part B: Polymer Physics, vol. 42, pp. 2690-2702, 2004.

7. Raid Al-Khateeb, Haider T. Naeem \& Baleeghsood Abdul, "Influence of Gas Oil on Compressive Strength of Concrete ",International Journal of General Engineering and Technology (IJGET), Vol. 3, Issue 1,pp, 51-56

8. J. J. Brennan and K. M. Prewo, "Silicon carbide fibre reinforced glass-ceramic matrix composites exhibiting high strength and toughness, "Journal of Materials Science, vol. 17, pp. 2371-2383, 1982.

9. B. V. Ramnath, C. Elanchezhian, M. Jaivignesh, S. Rajesh, C. Parswajinan, and A. S. A. Ghias, "Evaluation of mechanical properties of aluminium alloy-alumina-boron carbide metal matrix composites, "Materials \& Design, vol. 58, pp. 332-338, 2014.

10. Aanal Shah \& C.B.Shah, "Influence of Alkaline Activators and Temperature on Strength Properties of GGBS based Geopolymer Concrete ",International Journal of Civil Engineering (IJCE) ISSN (P): 2278-9987; ISSN (E): 2278-9995 Vol. 6, Issue 3,pp; 21 28

11. D. J. Lloyd, H. Lagace, A. McLeod, and P. L. Morris, "Microstructural aspects of aluminium-silicon carbide particulate composites produced by a casting method,"Materials Science and Engineering: A, vol. 107, pp. 73-80, 1989.

12. A. Evans, C. San Marchi, and A. Mortensen, "Metal matrix composites," in Metal Matrix Composites in Industry, ed: Springer, 2003, pp. 9-38.

13. O. El-Kady and A. Fathy, "Effect of SiC particle size on the physical and mechanical properties of extruded Al matrix nanocomposites, "Materials \& Design (1980-2015), vol. 54, pp. 348-353, 2014.

14. L. A. Dobrzański, A. Włodarczyk, and M. Adamiak, "The structure and properties of PM composite materials based on EN AW2124 aluminum alloy reinforced with the BN or Al2O3 ceramic particles, "Journal of Materials Processing Technology, vol. 175, pp. 186-191, 2006.

15. S. O. Akinwamide, O. J. Akinribide, and P. A. Olubambi, "Microstructural evolution, mechanical and nanoindentation studies of stir cast binary and ternary aluminium based composites, "Journal of Alloys and Compounds, vol. 850, p. 156586, 2021.

16. H. Xiaoyu, L. Changming, L. Xunjia, L. Guanghui, and L. Fuqiang, "Aluminum alloy pistons reinforced with SiC fabricated by centrifugal casting,"Journal of Materials Processing Technology, vol. 211, pp. 1540-1546, 2011.

17. P. B. Pawar and A. A. Utpat, "Development of Aluminium Based Silicon Carbide Particulate Metal Matrix Composite for Spur Gear, "Procedia Materials Science, vol. 6, pp. 1150-1156, 2014.

18. H. S. Lee, K. Y. Jeon, H. Y. Kim, and S. H. Hong, "Fabrication process and thermal properties of SiCp/Al metal matrix composites for electronic packaging applications, "Journal of materials science, vol. 35, pp. 6231-6236, 2000.

19. R. E. Belke Jr, G. F. Trojanowski, and L. Zakraysek, "Metal matrix composite and structure using metal matrix composites for electronic applications," ed: Google Patents, 1989.

20. N. Radhika and R. Raghu, "Development of functionally graded aluminium composites using centrifugal casting and influence of reinforcements on mechanical and wear properties, "Transactions of Nonferrous Metals Society of China, vol. 26, pp. 905 916, 2016.

21. I. El-Galy, M. Ahmed, and B. Bassiouny, "Characterization of functionally graded Al-SiCp metal matrix composites manufactured by centrifugal casting, "Alexandria Engineering Journal, vol. 56, pp. 371-381, 2017.

22. A. O. Owoputi, F. L. Inambao, and W. S. Ebhota, "Effect of percentage weight and particle size of SiCp reinforcement on the mechanical behaviour of functionally graded aluminum metal matrix, "International Journal of Engineering Research and 
Technology, vol. 13, pp. 444-453, 2020.

23. X. Sun, M. Xie, G. Wang, H. Sun, A. S. Cavanagh, J. J. Travis, et al., "Atomic layer deposition of TiO2 on graphene for supercapacitors, "Journal of the Electrochemical Society, vol. 159, pp. A364-A369, 2012.

24. S. A. Lajevardi, T. Shahrabi, and J. A. Szpunar, "Synthesis of functionally graded nano Al2O3-Ni composite coating by pulse electrodeposition, "Applied Surface Science, vol. 279, pp. 180-188, 2013.

25. G. Jin, M. Takeuchi, S. Honda, T. Nishikawa, and H. Awaji, "Properties of multilayered mullite/Mo functionally graded materials fabricated by powder metallurgy processing, "Materials Chemistry and Physics, vol. 89, pp. 238-243, 2005.

26. T. R. Prabhu, "Processing and properties evaluation of functionally continuous graded 7075 Al alloy/SiC composites, "Archives of Civil and Mechanical Engineering, vol. 17, pp. 20-31, 2017.

27. Y. Watanabe, Y. Inaguma, H. Sato, and E. Miura-Fujiwara, "A novel fabrication method for functionally graded materials under centrifugal force: the centrifugal mixed-powder method,"Materials, vol. 2, pp. 2510-2525, 2009.

28. Y. Watanabe, I. S. Kim, and Y. Fukui, "Microstructures of functionally graded materials fabricated by centrifugal solid-particle andin-situ methods, "Metals and Materials International, vol. 11, pp. 391-399, 2005.

29. K. Liu, Y. Ma, M. Gao, G. Rao, Y. Li, K. Wei, et al., "Single step centrifugal casting TiAl automotive valves, "Intermetallics, vol. 13, pp. 925-928, 2005.

30. Y. Watanabe, N. Yamanaka, and Y. Fukui, "Control of composition gradient in a metal-ceramic functionally graded material manufactured by the centrifugal method,"Composites Part A: Applied Science and Manufacturing, vol. 29, pp. 595-601, 1998.

31. S. E. Saddow and A. K. Agarwal, Advances in silicon carbide processing and applications: Artech House, 2004.

32. B. Xiong, Z. Xu, Q. Yan, B. Lu, and C. Cai, "Effects of SiC volume fraction and aluminum particulate size on interfacial reactions in SiC nanoparticulate reinforced aluminum matrix composites, "Journal of Alloys and Compounds, vol. 509, pp. 1187-1191, 2011 .

33. S. A. Khadem, S. Nategh, and H. Yoozbashizadeh, "Structural and morphological evaluation of Al-5vol.\%SiC nanocomposite powder produced by mechanical milling, "Journal of Alloys and Compounds, vol. 509, pp. 2221-2226, 2011.

34. S. O. Akinwamide, S. M. Lemika, B. A. Obadele, O. J. Akinribide, O. E. Falodun, P. A. Olubambi, et al., "A nanoindentation study on Al (TiFe-Mg-SiC) composites fabricated via stir casting," in Key Engineering Materials, 2019, pp. 81-88.

35. D. Das, D. K. Roy, M. P. Satpathy, B. K. Nanda, and R.K.Nayak, "Compressive, impact and flexural behaviour of Al based metal matrix composites, "Materials Today: Proceedings, vol. 18, pp. 3080-3086, 2019.

36. B. Nayak, R. Sahu, and P. Karthikeyan, "Study of tensile and compressive behaviour of the in-house synthesized al-alloy nano composite, " in IOP Conference Series: Materials Science and Engineering, 2018, p. 012070.

37. T. Ye, Y. Xu, and J. Ren, "Effects of SiC particle size on mechanical properties of SiC particle reinforced aluminum metal matrix composite, "Materials Science and Engineering: A, vol. 753, pp. 146-155, 2019.

38. M. H. Rahman and H. M. Al Rashed, "Characterization of silicon carbide reinforced aluminum matrix composites, "Procedia Engineering, vol. 90, pp. 103-109, 2014. 